\title{
Quantitative analysis of gene expression in fixed colorectal carcinoma samples as a method for biomarker validation
}

\author{
BEATA OSTASIEWICZ ${ }^{1,2 *}$, PAWEŁ OSTASIEWICZ ${ }^{1 *}$, KAMILA DUŚ-SZACHNIEWICZ $^{1}$, \\ KATARZYNA OSTASIEWICZ ${ }^{3}$ and PIOTR ZIÓŁKOWSKI ${ }^{1}$
}

\author{
${ }^{1}$ Department of Pathology, Wrocław Medical University, Wrocław 50-368; ${ }^{2}$ Central Laboratory, Diagnostyka Sp. z o.o. \\ Medical Laboratories, Wrocław 50-041; ${ }^{3}$ Department of Statistics, Wrocław University of Economics, Wrocław 53-345, Poland
}

Received September 16, 2015; Accepted March 9, 2016

DOI: $10.3892 / \mathrm{mmr} .2016 .5200$

\begin{abstract}
Biomarkers have been described as the future of oncology. Modern proteomics provide an invaluable tool for the near-whole proteome screening for proteins expressed differently in neoplastic vs. healthy tissues. However, in order to select the most promising biomarkers, an independent method of validation is required. The aim of the current study was to propose a methodology for the validation of biomarkers. Due to material availability the majority of large scale biomarker studies are performed using formalin-fixed paraffin-embedded (FFPE) tissues, therefore these were selected for use in the current study. A total of 10 genes were selected from what have been previously described as the most promising candidate biomarkers, and the expression levels were analyzed with reverse transcription-quantitative polymerase chain reaction (RT-qPCR) using calibrator normalized relative quantification with the efficiency correction. For $6 / 10$ analyzed genes, the results were consistent with the proteomic data; for the remaining four genes, the results were inconclusive. The upregulation of karyopherin $\alpha 2$ (KPNA2) and chromosome segregation 1-like (CSE1L) in colorectal carcinoma, in addition to downregulation of chloride channel accessory 1 (CLCAI), fatty acid binding protein $1(F A B P 1)$, sodium channel, voltage gated, type VII $\alpha$ subunit (SCN7A) and solute carrier family 26 (anion exchanger), member 3 (SLC26A3) was confirmed. With the combined use of proteomic and genetic tools, it was reported, for the first time to the best of our knowledge, that SCN7A was downregulated in colorectal carcinoma at mRNA and protein levels. It had been previously suggested that the remaining five genes served an important role in colorectal
\end{abstract}

Correspondence to: Dr Paweł Ostasiewicz, Department of Pathology, Wrocław Medical University, 1 Marcinkowskiego, Wrocław 50-368, Poland

E-mail: pawosta@o2.pl

*Contributed equally

Key words: RT-qPCR, differentially expressed genes, FFPE, colorectal cancer, biomarkers carcinogenesis, however the current study provided strong evidence to support their use as biomarkers. Thus, it was concluded that combination of RT-qPCR with proteomics offers a powerful methodology for biomarker identification, which can be used to analyze FFPE samples.

\section{Introduction}

Neoplastic diseases are the second major cause of mortality in modern societies, and colorectal carcinoma is one of the most prevalent types (1). Biomarkers are prevalent and important in modern medicine. They enable earlier detection of cancer and aid in the prediction of prognosis. However, routine use of biomarkers remains low (2).

Proteomic technology can aid in more rapid progress in the search for biomarkers. However, despite more than 15 years of proteomic research, no effective novel biomarkers have been identified for colorectal carcinoma, hundreds of candidate biomarkers have been identified, however none are currently used in clinical practice $(3,4)$. A key difficulty is the selection of biomarkers for further investigation; due to the fact that clinical trials for biomarker validation are expensive, it is important to select the most promising candidates. Unfortunately, in the majority of cases, promising proteins selected vary between studies, likely due to the differing protocols used. Quantitative data in proteomics are obtained in relation to external or internal standards, and since the standards used are different in each experiment, comparing the results is very difficult. Quantitative data has been previously published (5). Being aware of the controversies existing around the label-free proteomics methods (6), it was decided to validate the most promising biomarkers with a method widely recognized as being reliable in quantitative analysis, the reverse transcription-quantitative polymerase chain reaction (RT-qPCR) method.

Formalin-fixed paraffin-embedded (FFPE) samples are widely available in large numbers, often with clinical and outcome information attached, making them ideal for biomarker studies. In the current study, routinely processed, archival FFPE samples were used. Although it is widely known that RNA isolated from FFPE tissue is highly degraded (7-11) it has become more commonly accepted that in spite of the poor RNA quality, gene expression 
analysis from the fixed tissue is possible. According to the literature, use of short amplicons and normalization with more than one reference gene increases the accuracy of the measurements $(11,12)$. It has also been previously identified that this approach can be applied to the analysis of colorectal carcinoma (10).

\section{Materials and methods}

Human FFPE specimens. Archival FFPE samples of cancer and adjacent normal colon tissue were obtained from the Pathology Department of Wrocław Medical University (Wrocław, Poland). The study was approved by the ethics committee of Wrocław Medical University. For the purpose of the investigation thirteen blocks containing tumor tissues and four blocks containing negative surgical margins (used as an approximation of healthy tissue) were selected. Detailed characteristics of the examined patients are provided in Table I.

RNA isolation. All work was conducted under conditions that minimized the exposure to RNases. The bench surface, all the equipment and the glass slides were cleaned with RNaseZap RNase Decontamination solution (Ambion; Thermo Fisher Scientific, Inc., Waltham, MA, USA) prior to their use, according to the manufacturer's instructions. Diethyl pyrocarbonate (DEPC; Sigma-Aldrich, St. Louis, MO, USA)-treated water and hematoxylin $(0.1 \%, \mathrm{v} / \mathrm{v})$ were used throughout the histology procedures.

The FFPE blocks were cut using a standard microtome (Reichert-Jung Hn40; Leica Microsystems GmbH, Wetzlar, Germany) into $10-\mu \mathrm{m}$ sections, which were then mounted onto glass slides (Superfrost; Menzel-Glaser; Thermo Fisher Scientific, Inc., Braunschweig, Germany). In each case, the first four sections were discarded to exclude any negative effects due to exposure to air. In order to avoid any contamination, a new microtome blade was used for each block.

All sections were incubated on a hotplate at $70^{\circ} \mathrm{C}$ for $1 \mathrm{~min}$ and then were deparaffinized in two changes of xylene (Stanlab Sp. J., Lublin, Poland) for 3 and $2 \mathrm{~min}$. Subsequently the samples were rinsed in alcohol (95\% solution for $1 \mathrm{~min}$ and then $70 \%$ solution for $90 \mathrm{sec}$ ) and finally in DEPC water for $90 \mathrm{sec}$. To identify the tumor-enriched area, sections were stained with DEPC-treated hematoxylin solution (Sigma-Aldrich) for $20 \mathrm{sec}$ and finally rinsed in DEPC-treated water for $1 \mathrm{~min}$.

The cancer cells or healthy epithelium were scraped off the glass slides using sterile, RNaseZap-treated, single-use needle. Subsequently, they were transferred to nuclease-free $1.5 \mathrm{ml}$ microcentrifuge tubes (Eppendorf, Hamburg, Germany) and dried in $37^{\circ} \mathrm{C}$ for $2 \mathrm{~min}$. Microdissection was performed by the pathologist with microlance 3-26 G single-use needles (BD Biosciences, Franklin Lakes, NJ, USA) subsequent to microscopic examination of each slide with a Eclipse Ci microscope (Nikon Corporation, Tokyo, Japan). Approximately $1 \mathrm{~cm}^{2}$ of tissue was scraped off for each isolation and two independent RNA isolations were performed for each FFPE block.

Total RNA was isolated with the High Pure RNA Paraffin kit (\#03270289001; Roche Diagnostics, Basel,
Switzerland) according to the manufacturer's instructions, with certain modifications. Briefly, $100 \mu \mathrm{l}$ tissue lysis buffer, $16 \mu 110 \%$ sodium dodecyl sulfate and $40 \mu \mathrm{l}$ proteinase $\mathrm{K}$ $(20 \mathrm{mg} / \mathrm{ml})$ from the kit were added to each sample, vortexed with a ZX3 Advanced Vortex Mixer (VELP Scientifica SRL, Usmate, Italy) and then incubated at $55^{\circ} \mathrm{C}$ for $17 \mathrm{~h}$. RNA was pooled by adding two lysates to each High Pure Filter tube. All purification, DNase treatment, subsequent digestion with proteinase $\mathrm{K}$ and all other steps were performed according to the manufacturer's protocol. RNA was then resuspended in $50 \mu \mathrm{l}$ Elution buffer. Once the RNA was extracted, it was then DNase treated to remove any DNA contamination. DNA was eliminated using the RNase-Free DNase Set (Qiagen GmbH, Hilden, Germany) and the Rneasy Mini kit (Qiagen $\mathrm{GmbH}$ ). DNase digestion was performed twice: First in the eluate and then on-column. All steps were performed according to the manufacturer's instructions.

The final volume of each sample was $30 \mu 1$. The purified total RNA was stored at $-80^{\circ} \mathrm{C}$ until used for cDNA synthesis.

Nucleic acid measurements. The concentration and the purity of the RNA were measured with the Picodrop Microliter UV/Vis Spectrophotometer (Picodrop, Ltd., Hinxton, UK). The purity of the RNA was determined by measuring the absorbance ratio A260/A280, with the ratio value 2.0 being accepted as 'pure' RNA. The total amount of nucleic acids (RNA, DNA) and proteins was assessed by the Qubit 2.0 Fluorometer (Life Technologies; Thermo Fisher Scientific, Inc., Waltham, MA, USA). The Qubit measurability limit for proteins is $1.0 \mu \mathrm{g} / \mathrm{ml}$. The measurements of the RNA concentration were conducted using Picodrop and Qubit a minimum of 2 times for each sample, and the results are presented as the mean \pm standard deviation. Prior to the RT-qPCR reaction, all the samples were applied to a concentration of $600 \mathrm{ng} / \mu \mathrm{l}$.

The total RNA and mRNA integrity, purity and concentration were assessed by capillary electrophoresis using an Experion Bioanalyzer, Experion RNA HighSens Chips and Experion software, version 3.20 (Bio-Rad Laboratories, Inc., Hercules, CA, USA) following the manufacturer's protocol.

cDNA synthesis. A reverse transcription reaction was performed in a $20 \mu \mathrm{l}$ volume in a PTC-100 Programmable Thermal Controller (MJ Research, Inc., Quebec, Canada) using the Transcriptor First Strand cDNA Synthesis kit (\#04379012001; Roche Diagnostics) according to the manufacturer's instructions, with certain modifications.

The components of the Transcriptor kit were used as follows: Total RNA $(3 \mu \mathrm{l} ; 600 \mathrm{ng} / \mu \mathrm{l}), 50 \mathrm{pmol} / \mu \mathrm{l}$ Anchored Oligo $(\mathrm{dT})_{18}$ Primers (final concentration $2.5 \mu \mathrm{M}$ ) and $600 \mathrm{pmol} / \mu 1$ Random Hexamer Primers (final concentration, $60 \mu \mathrm{M}$ ) were heated in $7 \mu \mathrm{l}$ RNase-free water at $65^{\circ} \mathrm{C}$ for $10 \mathrm{~min}$ and immediately chilled on ice. A mixture consisting $4 \mu 1$ Transcriptor RT Reaction buffer (final concentration of $\mathrm{MgCl}_{2}, 8 \mathrm{mM}$ ), $0.5 \mu \mathrm{l}$ Protector RNase Inhibitor (40 U/ $\mu \mathrm{l}$; final concentration, $20 \mathrm{U}$ ), $2 \mu 110 \mathrm{mM}$ dNTP mix (final concentration $1 \mathrm{mM}$ each for the four deoxyribonucleoside triphosphates; dATP, dCTP, dGTP and dTTP) and $0.5 \mu 1$ Transcriptor Reverse Transcriptase (20 U/ $\mu$ i; final concentration, $10 \mathrm{U}$ ) were added to the RNA solution and incubated at $25^{\circ} \mathrm{C}$ for $10 \mathrm{~min}$, followed by $30 \mathrm{~min}$ at $55^{\circ} \mathrm{C}$. Finally, 
Table I. Clinicopathological characteristics of study patients.

\begin{tabular}{ccccc}
\hline Patient & Gender/age & Grade & pTNM & Stage \\
\hline 1 & M/78 & G2 & pT3N1Mx & III \\
2 & M/76 & G1 & pT3N1Mx & III \\
3 & M/89 & G2 & pT2N1Mx & III \\
4 & M/62 & G2 & pT4N1Mx & III \\
5 & F/84 & G2 & pT3N0Mx & II \\
6 & M/69 & G2 & pT4N0Mx & II \\
7 & M/77 & G2 & pT4N2M1 & III \\
8 & F/57 & G2 & pT2N2Mx & III \\
9 & F/76 & G2 & pT3NOMx & II \\
10 & M/58 & G3 & pT2N1Mx & III \\
11 & F/75 & G2 & pT2N2M1 & IV \\
12 & F/57 & G2 & pT2N2Mx & III \\
13 & F/77 & G2 & pT1N2Mx & III \\
\hline
\end{tabular}

TNM, tumor, node, metastasis; M, male; F, female.

Transcriptor Reverse Transcriptase was inactivated by heating the reaction mixture to $85^{\circ} \mathrm{C}$ for $5 \mathrm{~min}$. Samples were immediately cooled on ice. The obtained cDNA $(20 \mu \mathrm{l})$ was stored at $-20^{\circ} \mathrm{C}$.

$R T-q P C R$. The RT-qPCR reaction was performed using the LightCycler 480 Instrument and RealTime Ready Custom panels (Roche Diagnostics), the ready to use LightCycler 480 Multiwell Plate 96 (Roche Diagnostics). Each well of the Multiwell Plate 96 contained both forward and reverse gene specific primers ( $8 \mathrm{pmol} /$ primer) for the selected target and one Universal Probe Library probe (4 pmol), all pre-plated in the wells.

The total volume of the reaction was $20 \mu 1$. Each reaction mixture consisted of $3 \mu 1$ reverse transcription reaction product as the template, $7 \mu \mathrm{l}$ PCR grade water and $10 \mu 1$ LightCycler 480 Probes Master (Roche Diagnostics) containing FastStart Taq DNA Polymerase, reaction buffer, dNTP mix (with dUTP instead of dTTP) and $6.4 \mathrm{mM} \mathrm{MgCl}_{2}$ (all Roche Diagnostics). The RT-qPCR reaction was completed with an initial denaturation step $\left(95^{\circ} \mathrm{C}\right.$ for $\left.10 \mathrm{~min}\right)$ followed by 55 cycles of denaturation $\left(95^{\circ} \mathrm{C}, 10 \mathrm{sec}\right)$, annealing $\left(60^{\circ} \mathrm{C}\right.$, $30 \mathrm{sec})$ and extension $\left(72^{\circ} \mathrm{C}, 1 \mathrm{sec}\right)$. A final cooling step was conducted at $40^{\circ} \mathrm{C}$ for $30 \mathrm{sec}$. Samples were analyzed in duplicates or triplicates.

A total of 10 genes from neoplastic tissues [karyopherin $\alpha 2$ (KPNA2), chloride channel accessory 1 (CLCA1), transcription elongation factor A (SII) (TCEAI), G proteincoupled receptor, class $\mathrm{C}$, group 5 , member A (GPRC5A), paralemmin 3 (PALM3), chromosome segregation 1-like (CSEIL), fatty acid binding protein $1(F A B P 1)$, high mobility group nucleosome-binding domain-containing protein 1 (HMGN1), sodium channel, voltage gated, type VII $\alpha$ subunit (SCN7A) and solute carrier family 26 (anion exchanger), member 3 (SLC26A3)] and 6 genes in the healthy tissues (KPNA2, CLCA1, TCEA1, CSEIL, FABPI and HMGNI) were examined. The following primer sequences were used:
KPNA2, F 5'-GCATAAATAGCAGCAATGTGGA-3' and R 5'-GGGGCTGTTTTTCTCTGGA-3'; CLCA1, F 5'-TCA TCAGGAAATGGAGCTGTC-3' and R 5'-CTGGCTGTT CTGGAGGGTTA-3'; TCEA1, F 5'-TTAAGGAAAAATGTC CTCTGTGG-3' and R 5'-GGTCAAGTTTTTCCGCATCT-3'; GPRC5A, F 5'-TCA AGAGGA AATCACTCA AGGTT-3' and R 5'-GTGGGATGGAGAATTCCTTTT-3'; PALM3, F 5'-GCACGTCCACCTAAACCTG-3' and R 5'-GGCTTC ATCGCAGAAGGA-3'; CSE1L, F '-AGGTTATTGTGCCTA ACATGGAA-3' and R 5'-TCCTCAGAATTATCTTCAAAT GCTT-3'; FABPI, F 5'-GCAGAGCCAGGAAAACTTTG-3' and $\mathrm{R}$ 5'-CCTTCCCCTTCTGGATGAG-3'; HMGNI, F 5'-AGACTTACCTGCGGAAAACG-3' and R 5'-TGG CTTCTTTCTCTCCTGCTT-3'; SCN7A, F 5'-AAGGAG ATTCAGAGTAAGTCTGGTG-3' and R 5'-CATTCAGAT GAGCTAGATTGCTTT-3'; and SLC26A3, F 5'-ATTGTG GCGAAAGGACAAAT-3' and R 5'-ACTAGCTGCCAG GCCTAACC-3'. RT-qPCR was performed using calibrator normalized relative quantification with the efficiency correction. Peptidylprolyl isomerase A (cyclophilin A) (F TTC ATCTGCACTGCCAAGAC and R CACTTTGCCAAACAC CACAT) and $\beta$-actin (F TCCTCCCTGGAGAAGAGCTA and R CGTGGATGCCACAGGACT) were used as reference genes in the analysis. A mixture of RNA isolated from the healthy mucosa of four patients was used as a calibrator. The RT-qPCR efficiency differences were corrected with the standard curves made for each reference and each target gene. The negative controls were prepared by omitting the addition of the reverse transcriptase to the cDNA synthesis reaction. 'Pure' DNA samples were considered those that exhibited no growth following 55 cycles of RT-qPCR. The positive controls consisted of three assays, each one targeting different portions of the same transcript: At the 3'-end, in the middle and at the 5'-end. Obtained data was analyzed with the LightCycler 480 Multiple Plate Analysis Software (Roche Diagnostics).

Statistics. Statistical analysis was performed using the Mathematica program, version 7 (Wolfram Research Europe, Ltd., Witney, UK). The linear models were built using all potentially significant variables; the genes of which expression levels in cancer tissues were significantly different from the levels in healthy tissues. Subsequent to estimating the values of the coefficients, all the insignificant variables were removed and the process was repeated, until a consistent model with significant parameters was obtained.

Clustering of all samples was performed using Mathematica. The Euclidean distance functions (between the expression levels of either all 4 significant genes or the 2 most significant genes) were taken into account as a measure of similarity. A total of two clusters were required, and a Logit model was built using the maximum likelihood method of parameter estimation.

\section{Results}

A total of 10 proteins either up- or downregulated in cancer were selected from a previously published proteomic study (5). RT-qPCR was performed using calibrator normalized relative quantification with the efficiency correction. The complete 
list of the analyzed genes/proteins with aliases and additional information including functional class, amplicon length, intron spanning and position and transcript length is provided in Table II. Short amplicons [67-113 base pairs (bps)] were used, which are preferable in the case of highly degraded RNA (12).

Capillary electrophoresis was performed for all samples and for the calibrator and the results are presented in Fig. 1. The concentration of the isolated RNA, calculated RNA quality indicator and the concentration of contaminating DNA and proteins is presented in Table III. Due to the fact that all negative controls exhibited no growth after 55 cycles, it was concluded that the concentration of contaminating DNA was too low to interfere with the RT-qPCR results. Negative controls for each sample were prepared by omitting the reverse transcription step, and running together with the samples.

In the current study, the expression levels of 10 genes in cancer vs. healthy tissues in samples obtained with needle microdissection from 13 patients were analyzed. The results are presented in Table IV.

Out of the 10 analyzed genes, 6 exhibited statistically significant different expression levels in the neoplastic vs. healthy mucosa. Out of 6 proteins upregulated according to a previous proteomic study (5), only in 2 cases was statistically significant upregulation in gene expression observed in the current study. By contrast, out of 4 downregulated proteins, statistically significant gene expression was observed in all cases. The results are presented in Table V.

For the 6 genes analyzed in healthy and neoplastic tissues, cluster analysis was conducted. When the four significantly changed genes (KPNA2, CSE1L, CLCA1 and FABPI) were analyzed together, certain cancer samples clustered together with the healthy samples. However, if the two most significantly altered genes (CLCAI and $F A B P 1)$ were considered alone, then all healthy samples were observed to be clustered together and were separate from the neoplastic samples. These observations were used to construct the logit model.

In addition, linear modeling was conducted for stage, and the tumor $(\mathrm{T})$ and necrosis $(\mathrm{N})$ features separately. It was identified that only the CLCA1 and FABPI genes served significant roles in these models. It was identified that the variability of gene expression for CLCA1 accounted for $68 \%$ of the variability of the cancer stage (coefficient of determination $=68 \%$ ). In addition, expression of $C L C A 1$ was observed to be reduced by 3.1 times, while the stage was increased by 1 . Concerning $\mathrm{T}$, the expression of one gene was observed to be statistically significant, $F A B P 1$, and its variability accounted for $61 \%$ of the variability of T. Expression of $F A B P 1$ was reduced by 2.4 times as the $\mathrm{T}$ feature increased by 1 . For the $\mathrm{N}$ feature, the expression of one gene was observed to be statistically significant, CLCA1. However, its variability accounted for $27 \%$ of the total variability, which was low compared with the $61 \%$ observed for $\mathrm{T}$ and the $68 \%$ for stage.

\section{Discussion}

The importance of CSE1L in colorectal carcinoma has been previously suggested in numerous studies, however its precise role remains to be fully elucidated (13-17). CSE1L was selected for inclusion in the current study as a positive control.
Additionally, the aim of the current study was to investigate whether it was possible to analyze CSE1L expression in FFPE samples, due to the fact that the majority of previous studies utilized immunohistochemistry. CSE1L serves an important role in the mediation of apoptosis and invasion of neoplastic cells $(13,17,18)$. Notably, an increase in the levels of CSE1L in the sera of patients with metastasis was also reported (16). CSE1L is located on chromosome 20q; and upregulation of this chromosome has been previously reported as a common event in colorectal carcinogenesis (19). It has been previously suggested that CSE1L expression correlates with tumor stage and prognosis, however currently available data remains inconclusive $(14,16,17)$. Utilization of archival FFPE samples with survival data should allow for the analysis of CSE1L expression in larger cohorts leading to more reliable conclusions. The results of the current study indicate that in the majority of cases of colorectal carcinoma there is an overexpression of CSE1L. These results are in agreement with a previously published gene expression study utilizing fresh tissues (17). In the current study, it was identified that quantitative analysis of CSE1L expression with RT-qPCR from fixed samples is possible. Due to the limited number of patients included, the association between gene expression and stage cannot be confirmed.

The KPNA2 protein remains to be fully investigated, however a previous study suggested that it serves a near-universal role in carcinogenesis (20). It was recently suggested that KPNA2 regulates the subcellular localization of DNA damage response proteins (21), and correlates with the proliferation activity (22). Data on KPNA2 expression in colorectal carcinoma remains limited, however a previous study indicated that KPNA2 is overexpressed in this malignancy (20).

As described above, a logit model was constructed on two genes, $C L C A 1$ and $F A B P 1$, of which the expression levels separated healthy samples from neoplastic samples in the cluster analysis. Due to the small sample size, the coefficients of the logit model were not observed to be significant. As there is limited existing data, expression analysis of CLCA1 and FABPI allows the 'prediction' (via a logit model) of the status of tissues (cancer vs. healthy) with a probability close to 1 . Thus, it may be the case that expression analysis of these two genes in larger groups is a promising direction for further studies.

The role of CLCA1 in carcinogenesis remains to be fully elucidated, with only five reports investigating the significance of CLCA1 in cancer progression (23-27) and three concerning colorectal neoplasia $(23,26,27)$ identified in the search conducted. It has been suggested that CLCAI acts as a tumor suppressor gene by suppressing Bcl-2 overexpression in response to cell swelling (26). Notably, data from ovarian cancer analysis indicated that CLCAl was overexpressed during cancer progression (24). This is in contrast to the downregulation of CLCAI in colorectal carcinogenesis, reported in numerous previous studies $(23,26,27)$. A paper published in 2015 reported that there was a correlation between poorer prognosis and lower expression levels of CLCA1 in colorectal carcinoma, assessed by immunohistochemistry (26). To the best of our knowledge, the current study is the first genetic study to indicate a negative correlation between the cancer stage and CLCAI expression.

A greater number of studies have been conducted investigating the significance of $F A B P 1$ in carcinogenesis, than 

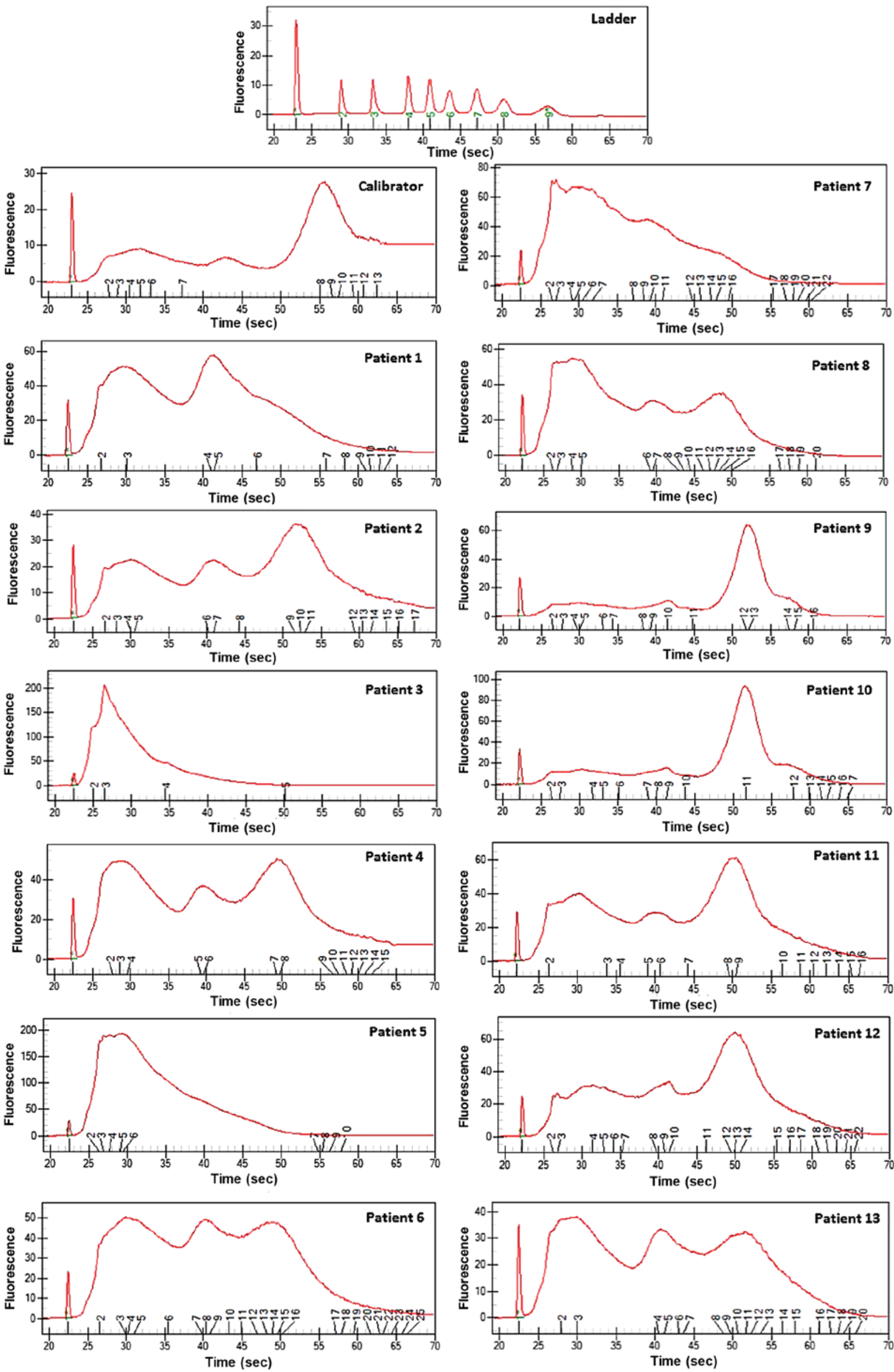

Figure 1. Capillary electrophoresis of all analyzed samples. 
Table II. Characteristics of investigated genes.

\begin{tabular}{|c|c|c|c|c|}
\hline Protein & $\begin{array}{c}\text { Gene } \\
\text { symbol }\end{array}$ & $\begin{array}{l}\text { Amplicon } \\
\text { length (bps) }\end{array}$ & $\begin{array}{l}\text { Intron spanning } \\
\text { and position }\end{array}$ & $\begin{array}{c}\text { Transcript } \\
\text { length (bps) }\end{array}$ \\
\hline \multicolumn{5}{|l|}{ Nuclear transporters } \\
\hline Importin subunit $\alpha 2$ & KPNA2 & 81 & Yes/435 & 1,979 \\
\hline Exportin 2 & CSE1L & 67 & Yes/1,190 & 3,553 \\
\hline \multicolumn{5}{|l|}{ Non-nuclear channels and transporters } \\
\hline Calcium-activated chloride channel regulator 1 & CLCA1 & 75 & Yes/1,594 & 3,118 \\
\hline Fatty acid-binding protein, liver & $F A B P 1$ & 74 & Yes/167 & 546 \\
\hline Sodium channel protein type 7 subunit $\alpha$ & $S C N 7 A$ & 71 & Yes/2,720 & 5,727 \\
\hline Chloride anion exchanger & $S L C 26 A 3$ & 94 & Yes/1,593 & 2,863 \\
\hline \multicolumn{5}{|l|}{ General transcription factors } \\
\hline Transcription elongation factor S-II & TCEAI & 108 & Yes/1,002 & 1,226 \\
\hline \multicolumn{5}{|l|}{ High mobility group proteins } \\
\hline High mobility group protein N1 & HMGN1 & 77 & Yes/459 & 1,303 \\
\hline \multicolumn{5}{|l|}{ Plasma membrane proteins } \\
\hline Retinoicacid-induced protein 3 & GPRC5A & 113 & Yes/1,573; 1,632 & 2,849 \\
\hline Paralemmin 3 & PALM3 & 76 & No & 2,260 \\
\hline
\end{tabular}

bps, base pairs.

Table III. RNA isolation results (formalin-fixed paraffin-embedded human colon).

\begin{tabular}{|c|c|c|c|c|}
\hline Patient & $\begin{array}{c}\text { Concentration } \\
(\mathrm{ng} / \mu \mathrm{l})\end{array}$ & RQI & $\begin{array}{l}\text { gDNA (ng) in } \\
100 \text { ng RNA }\end{array}$ & $\begin{array}{l}\text { Protein } \\
(\mu \mathrm{g} / \mathrm{ml})\end{array}$ \\
\hline 1 & 759 & 3.5 & 2.9 & $<1.0$ \\
\hline 2 & 520 & 3.5 & 9.3 & $<1.0$ \\
\hline 3 & 1101 & Critical anomaly & 2.1 & $<1.0$ \\
\hline 4 & 716 & 6.2 & 3.6 & $<1.0$ \\
\hline 5 & 1381 & 1.8 & 2.1 & $<1.0$ \\
\hline 6 & 763 & 3.5 & 2.3 & $<1.0$ \\
\hline 7 & 721 & 2.4 & 2.2 & $<1.0$ \\
\hline 8 & 645 & 3.1 & 2.5 & $<1.0$ \\
\hline 9 & 520 & 2.9 & 3.2 & $<1.0$ \\
\hline 10 & 838 & 2.5 & 2.4 & $<1.0$ \\
\hline 11 & 679 & 3.0 & 2.6 & $<1.0$ \\
\hline 12 & 651 & 2.5 & 2.8 & $<1.0$ \\
\hline 13 & 643 & 3.4 & 3.2 & $<1.0$ \\
\hline Calibrator & 652 & 3.7 & 4.1 & $<1.0$ \\
\hline
\end{tabular}

RQI calculated by Experion software. RQI, RNA quality indicator; gDNA, genomic DNA.

that for CLCA1. Previous studies (28-30) have reported the downregulation of FABP1 in colorectal carcinogenesis; with a correlation between poorer prognosis and lower expression levels of $F A B P 1$ in liver metastasis also reported (31). An immunohistochemical study reported a correlation between tumor grade and FABP1 expression, however no correlation between stage and FABP1 expression was identified (29). To the best of our knowledge, the current study was the first to demonstrate an association between tumor size and FABP1 expression. Notably, although for hepatocellular carcinoma the association between FABP1 expression and prognosis is similar to that in colorectal carcinoma (32), in gastric carcinoma $(33,34)$ and pancreatic carcinoma $(35)$ the association was the opposite; FABP1 expression was observed to increase throughout cancer development.

SLC26A3 was previously identified as a potential tumor suppressor gene involved in colorectal carcinogenesis (36). Subsequent to the identification of an association between 
Table IV. Gene expression ratios, cancer:normal (calibrator) for 13 individual patients.

\begin{tabular}{|c|c|c|c|c|c|c|c|c|c|c|c|c|c|}
\hline \multirow[b]{2}{*}{ Gene } & \multicolumn{13}{|c|}{ Patient } \\
\hline & 1 & 2 & 3 & 4 & 5 & 6 & 7 & 8 & 9 & 10 & 11 & 12 & 13 \\
\hline KPNA2 & 9.89 & 3.53 & 8.73 & 12.8 & 17.83 & 3.36 & 11.55 & 7.73 & 2.16 & 6.65 & 3.14 & 4.58 & 9.59 \\
\hline CSEIL & 13.7 & 10.68 & 2.5 & 4.27 & 0.73 & 2.42 & 3.85 & 2.07 & 4.46 & 3.51 & 1.88 & 2.1 & 6.71 \\
\hline CLCAI & 0 & $1.09 \times 10^{-8}$ & 0.02 & 0 & 0 & 0 & 0.007 & 0.001 & 0 & 0 & 0.03 & 0.002 & 0.0001 \\
\hline$F A B P 1$ & 0.19 & 0.03 & 0.28 & 0.007 & 0.0009 & 0.01 & 0.05 & 0.3 & 0.06 & 0.002 & 0.03 & 0.40 & 0.05 \\
\hline SCN7A & 0 & 0 & 0.06 & 0 & 0.02 & 0.28 & 0.1 & 0.27 & 0 & 0.008 & 0.17 & 0.03 & 0 \\
\hline$S L C 26 A 3$ & 0 & 0.003 & 0.01 & 0 & 0.007 & 0.003 & 0.00007 & 0.008 & 0.001 & 0 & 0.0004 & 0.03 & $2.52 \times 10^{-8}$ \\
\hline TCEAl & 2.89 & 0.78 & 0.48 & 1.35 & 0.59 & 1.78 & 2.05 & 0.9 & 0.33 & 0.78 & 0.5 & 0.75 & 1.4 \\
\hline HMGN1 & 8.5 & 0.69 & 0.62 & 1.8 & 0.35 & 0.83 & 0.5 & 0.59 & 0.59 & 0.83 & 0.88 & 0.62 & 1.3 \\
\hline GPRC5A & 9.93 & 0.15 & 0.46 & 1.41 & 1.49 & 1.09 & 0.47 & 0.51 & 0.62 & 0.34 & 0.25 & 0.61 & 1.16 \\
\hline PALM3 & 8.61 & 0.07 & 4.45 & 0.27 & 0.34 & 163.5 & 2.04 & 0.81 & 0.19 & 0.13 & 10.44 & 1.68 & 10.67 \\
\hline
\end{tabular}

Scores of 0 were considered as cancer samples with no growth after 55 cycles whereas the calibrator exhibited a constant $\mathrm{Cp}$ in all cases.

Table V. Gene expression ratios in comparison with proteomic data.

\begin{tabular}{|c|c|c|c|c|c|c|}
\hline \multirow[b]{2}{*}{ Protein } & \multirow[b]{2}{*}{ Gene } & \multicolumn{2}{|c|}{ Proteomic study (5) } & \multicolumn{3}{|c|}{ Present study } \\
\hline & & $\begin{array}{l}\text { Average } \\
\mathrm{C} / \mathrm{N} \text { ratio }\end{array}$ & P-value & $\begin{array}{l}\text { Average } \\
\mathrm{C} / \mathrm{N} \text { ratio }\end{array}$ & $\begin{array}{l}\text { Standard } \\
\text { deviation }\end{array}$ & P-value \\
\hline Importin subunit $\alpha 2$ & KPNA2 & 5.8 & 0.0083 & 7.8 & 4.6 & 0.0002 \\
\hline Exportin 2 & CSE1L & 8.8 & 0.0033 & 4.5 & 3.8 & 0.007 \\
\hline Calcium-activated chloride channel regulator 1 & CLCA1 & 0.031 & 0.0010 & 0.0005 & 0.01 & $1.9 \times 10^{-25}$ \\
\hline Fatty acid-binding protein, liver & $F A B P 1$ & 0.16 & 0.0461 & 0.1 & 0.1 & $3.4 \times 10^{-11}$ \\
\hline Sodium channel protein type 7 subunit $\alpha$ & $S C N 7 A$ & 0.068 & 0.0186 & 0.07 & 0.1 & $7.7 \times 10^{-13}$ \\
\hline Chloride anion exchanger & $S L C 26 A 3$ & 0.12 & 0.00708 & 0.006 & 0.01 & $2.3 \times 10^{-25}$ \\
\hline Transcription elongation factor S-II & TCEAl & 4.5 & 0.0033 & 1.1 & 0.7 & 0.57 \\
\hline High mobility group protein $\mathrm{N} 1$ & $H M G N 1$ & 5.4 & 0.0047 & 1.4 & 2.2 & 0.54 \\
\hline Retinoicacid-induced protein 3 & GPRC5A & 131.0 & 0.0017 & 1.4 & 2.6 & 0.58 \\
\hline Paralemmin 3 & PALM3 & 22.8 & 0.0049 & 15.63 & 44.6 & 0.28 \\
\hline
\end{tabular}

Significant alterations in expression are indicated by P-values in bold. Data in columns 3 and 4 originate from previously published proteomic study (5). C, cancer; N, normal.

SLC26A3 and congenital chloride diarrhea (37), it was suggested as an electrolyte transporter. Previous studies have confirmed the downregulation of SLC26A3 in colorectal carcinoma (38-40), and this has been explained to be as a result of dedifferentiation (41). Notably, it has been reported that $S L C 26 A$-deficient mice exhibit enhanced colonic crypt proliferation (42) and that $S L C 26 A 3$ overexpression can inhibit growth of cancer cell lines in vitro (43). Patients with germline mutations in SLC26A3 have been demonstrated to exhibit a marginally increased risk of colorectal cancer (44). The data of the current study indicates that $S L C 26 A 3$ is downregulated in cancer, however this requires further investigation.

According to the UniProt database, SCN7A encodes for a voltage-dependent sodium channel of excitable membrane (45). No previous studies were identified that investigated the expression of SCN7A in colonic tissue, however data from The
Human Protein Atlas confirmed its presence in healthy and neoplastic colon epithelium (46). The only identified study concerning SCN7A significance in carcinogenesis reports its DNA mutation in adrenocortical carcinoma (47). To the best of our knowledge, the current study together with a previous proteomic study (5) are the first to report downregulation of $S C N 7 A$, confirmed on genetic and proteomic levels.

For TCEA1, HMGN1, GPCR5A and PALM3, no statistically significant differences were observed. Although the results obtained with genetic methods are not contrary to those obtained with proteomic methods, there are considerable differences between the P-values obtained for each gene/protein. The absence of significance observed in the present study is suggested to be due to the extensive variability in the expression ratios. Due to the fact that little is known about PALM3 and $H M G N 1$ significance in colorectal carcinogenesis, it is 
difficult to identify which set of results are more reliable. In the case of TCEA1, there is some evidence supporting the hypothesis that it is overexpressed in cancer $(48,49)$, however there are currently no studies investigating its expression in colorectal carcinoma. Previous studies $(50,51)$ have identified the overexpression of GPCR5A in a large patient cohort. There are at least two possible explanations for the differences between the results obtained in the proteomic and transcriptomic studies regarding TCEA1, HMGN1, GPCR5A and PALM3. Firstly, it is possible that the mRNA level does not necessarily correlate with the protein level. Alternatively, the discrepancies may be due to technical reasons associated with RT-qPCR and the degradation of RNA. In this context it is notable that the amplicons used for TCEA1 and GPCR5A were the longest used in the current study, at 108 and 113 bps, respectively.

In conclusion, the current study demonstrated that quantitative gene expression analysis from fixed material can be a valuable method used for the validation of potential biomarkers identified in other experiments, such as proteomic studies. However, this method may be suitable only for certain genes and requires careful experimental design and the use of shorter amplicons.

\section{Acknowledgements}

The current study was supported by the Polish National Science Center (grant no. DEC-2011/01/N/NZ5/04253). The authors would like to thank Mrs. Agnieszka Wójcik for her technical assistance.

\section{References}

1. Torre LA, Bray F, Siegel RL, Ferlay J, Lortet-Tieulent J and Jemal A: Global cancer statistics, 2012. CA Cancer J Clin 65: 87-108, 2015.

2. Vockley JG and Niederhuber JE: Diagnosis and treatment of cancer using genomics. BMJ 350: h1832, 2015.

3. Kondo T: Inconvenient truth: Cancer biomarker development by using proteomics. Biochim Biophys Acta 1844: 861-865, 2014.

4. Di Meo A, Diamandis EP, Rodriguez H, Hoofnagle AN, Ioannidis J and Lopez M: What is wrong with clinical proteomics? Clin Chem 60: 1258-1266, 2014.

5. Wiśniewski JR, Ostasiewicz P, Duś K, Zielińska DF, Gnad F and Mann M: Extensive quantitative remodeling of the proteome between normal colon tissue and adenocarcinoma. Mol Syst Biol 8: 611, 2012.

6. Sandin M,Chawade A andLevanderF: Is label-free LC-MS/MS ready for biomarker discovery? Proteomics Clin Appl 9: 289-294, 2015.

7. Farragher SM, Tanney A, Kennedy RD and Paul Harkin PD: RNA expression analysis from formalin fixed paraffin embedded tissues. Histochem Cell Biol 130: 435-445, 2008.

8. Ibusuki M, Fu P, Yamamoto S, Fujiwara S, Yamamoto Y, Honda $\mathrm{Y}$, Iyama $\mathrm{K}$ and Iwase $\mathrm{H}$ : Establishment of a standardized gene-expression analysis system using formalin-fixed, paraffin-embedded, breast cancer specimens. Breast Cancer 20: 159-166, 2013.

9. Walter RF, Mairinger FD, Wohlschlaeger J, Worm K, Ting S, Vollbrecht C, Schmid KW and Hager T: FFPE tissue as a feasible source for gene expression analysis-a comparison of three reference genes and one tumor marker. Pathol Res Pract 209: 784-789, 2013

10. Kalmar A, Wichmann B, Galamb O, Spisák S, Tóth K, Leiszter K, Tulassay Z and Molnár B: Gene expression analysis of normal and colorectal cancer tissue samples from fresh frozen and matched formalin-fixed, paraffin-embedded (FFPE) specimens after manual and automated RNA isolatio. Methods 59: S16-S19, 2013

11. Antonov J, Goldstein DR, Oberli A, Baltzer A, Pirotta M, Fleischmann A, Altermatt HJ and Jaggi R: Reliable gene expression measurements from degraded RNA by quantitative real-time PCR depend on short amplicons and a proper normalization. Lab Invest 85: 1040-1050, 2005.
12. Kong H, Zhu M, Cui F, Wang S, Gao X, Lu S, Wu Y and Zhu H: Quantitative assessment of short amplicons in FFPE-derived long-chain RNA. Sci Rep 4: 7246, 2014.

13. Zhu JH, Hong DF, Song YM, Sun LF, Wang ZF and Wang JW: Suppression of cellular apoptosis susceptibility (CSE1L) inhibits proliferation and induces apoptosis in colorectal cancer cells. Asian Pac J Cancer Prev 14: 1017-1021, 2013.

14. Tai CJ, Su TC, Jiang MC, Chen HC, Shen SC, Lee WR, Liao CF, Chen YC, Lin SH, Li LT, et al: Correlations between cytoplasmic CSE1L in neoplastic colorectal glands and depth of tumor penetration and cancer stage. J Transl Med 11: 29, 2013.

15. Sillars-Hardebol AH, Carvalho B, Beliën JA, de Wit M, Delis-van Diemen PM, Tijssen M, van de Wiel MA, Pontén F, Meijer GA and Fijneman RJ: CSE1L, DIDO1 and RBM39 in colorectal adenoma to carcinoma progression. Cell Oncol (Dordr) 35: 293-300, 2012.

16. Tung MC, Tsai CS, Tung JN, Tsao TY, Chen HC, Yeh KT, Liao CF and Jiang MC: Higher prevalence of secretory CSE1L/CAS in sera of patients with metastatic cancer. Cancer Epidemiol Biomarkers Prev 18: 1570-1577, 2009.

17. Alnabulsi A, Agouni A, Mitra S, Garcia-Murillas I, Carpenter B, Bird S and Murray GI: Cellular apoptosis susceptibility (chromosome segregation 1-like, CSE1L) gene is a key regulator of apoptosis, migration and invasion in colorectal cancer. J Pathol 228: 471-481, 2012.

18. Liao CF, Luo SF, Li LT, Lin CY, Chen YC and Jiang MC: CSE1L/CAS, the cellular apoptosis susceptibility protein, enhances invasion and metastasis but not proliferation of cancer cells. J Exp Clin Cancer Res 27: 15, 2008.

19. Brinkmann U, Gallo M, Polymeropoulos MH and Pastan I: The human CAS (cellular apoptosis susceptibility) gene mapping on chromosome 20q13 is amplified in BT474 breast cancer cells and part of aberrant chromosomes in breast and colon cancer cell lines. Genome Res 6: 187-194, 1996.

20. Rachidi SM, Qin T, Sun S, Zheng WJ and Li Z: Molecular profiling of multiple human cancers defines an inflammatory cancer-associated molecular pattern and uncovers KPNA2 as a uniform poor prognostic cancer marker. PLoS One 8: e57911, 2013.

21. Alshareeda AT, Negm OH, Green AR, Nolan CC, Tighe P, Albarakati N, Sultana R, Madhusudan S, Ellis IO and Rakha EA: KPNA2 is a nuclear export protein that contributes to aberrant localisation of key proteins and poor prognosis of breast cancer. Br J Cancer 112: 1929-1937, 2015.

22. Ma S and Zhao X: KPNA2 is a promising biomarker candidate for esophageal squamous cell carcinoma and correlates with cell proliferation. Oncol Rep 32: 1631-1637, 2014.

23. Bustin SA, Li SR and Dorudi S: Expression of the $\mathrm{Ca} 2+-$ activated chloride channel genes CLCA1 and CLCA2 is downregulated in human colorectal cancer. DNA Cell Biol 20: 331-338, 2001.

24. Musrap N, Tuccitto A, Karagiannis GS, Saraon P, Batruch I and Diamandis EP: Comparative proteomics of ovarian cancer aggregate formation reveals an increased expression of calcium-activated chloride channel regulator 1 (CLCA1). J Biol Chem 290: 17218-17227, 2015.

25. Muranen TA, Greco D, Fagerholm R, Kilpivaara O, Kämpjärvi K, Aittomäki K, Blomqvist C, Heikkilä P, Borg A and Nevanlinna H: Breast tumors from CHEK2 1100delC-mutation carriers: Genomic landscape and clinical implications. Breast Cancer Res 13: R90, 2011.

26. Yang B, Cao L, Liu J, Xu Y, Milne G, Chan W, Heys SD, McCaig CD and $\mathrm{Pu}$ J: Low expression of chloride channel accessory 1 predicts a poor prognosis in colorectal cancer. Cancer 121: 1570-1580, 2015.

27. Yang B, Cao L, Liu B, McCaig CD and Pu J: The transition from proliferation to differentiation in colorectal cancer is regulated by the calcium activated chloride channel A1. PLoS One 8: e60861, 2013

28. Lee S, Bang S, Song K and Lee I: Differential expression in normal-adenoma-carcinoma sequence suggests complex molecular carcinogenesis in colon. Oncol Rep 16: 747-754, 2006.

29. Lawrie LC, Dundas SR, Curran S and Murray GI: Liver fatty acid binding protein expression in colorectal neoplasia. Br J Cancer 90: 1955-1960, 2004.

30. Kheirelseid EA, Chang KH, Newell J, Kerin MJ and Miller N: Identification of endogenous control genes for normalisation of real-time quantitative PCR data in colorectal cancer. BMC Mol Biol 11: 12, 2010. 
31. Yamazaki T, Kanda T, Sakai Y and Hatakeyama K: Liver fatty acid-binding protein is a new prognostic factor for hepatic resection of colorectal cancer metastases. J Surg Oncol 72: 83-87, 1999.

32. Wang B, Tao X, Huang CZ, Liu JF, Ye YB and Huang AM: Decreased expression of liver-type fatty acid-binding protein is associated with poor prognosis in hepatocellular carcinoma. Hepatogastroenterology 61: 1321-1326, 2014.

33. Hashimoto T, Kusakabe T, Watanabe K, Sugino T, Fukuda T, Nashimoto A, Honma K, Sato Y, Kimura H, Fujii H and Suzuki T: Liver-type fatty acid-binding protein is highly expressed in intestinal metaplasia and in a subset of carcinomas of the stomach without association with the fatty acid synthase status in the carcinoma. Pathobiology 71: 115-122, 2004.

34. Satoh Y, Mori K, Kitano K, Kitayama J, Yokota H, Sasaki H, Uozaki H, Fukayama M, Seto Y and Nagawa H: Analysis for the combination expression of CK20, FABP1 and MUC2 is sensitive for the prediction of peritoneal recurrence in gastric cancer. Jpn J Clin Oncol 42: 148-152, 2012.

35. Sharaf RN, Butte AJ, Montgomery KD, Pai R, Dudley JT and Pasricha PJ: Computational prediction and experimental validation associating FABP-1 and pancreatic adenocarcinoma with diabetes. BMC Gastroenterol 11: 5, 2011.

36. Schweinfest CW, Henderson KW, Suster S, Kondoh N and Papas TS: Identification of a colon mucosa gene that is down-regulated in colon adenomas and adenocarcinomas. Proc Natl Acad Sci USA 90: 4166-4170, 1993.

37. Höglund P, Haila S, Socha J, Tomaszewski L, Saarialho-Kere U, Karjalainen-Lindsberg ML, Airola K, Holmberg C, de la Chapelle A and Kere J: Mutations of the down-regulated in adenoma (DRA) gene cause congenital chloride diarrhoea. Nat Genet 14: 316-319, 1996.

38. Kim HS, Kang SH, Park CH, Yang WI, Jeung HC, Chung HC, Roh JK, Ahn JB, Kim NK, Min BS and Rha SY: Genome-wide molecular characterization of mucinous colorectal adenocarcinoma using cDNA microarray analysis. Oncol Rep 25: 717-727, 2011.

39. Mlakar V, Berginc G, Volavsek M, Stor Z, Rems M and Glavac D: Presence of activating KRAS mutations correlates significantly with expression of tumour suppressor genes DCN and TPM1 in colorectal cancer. BMC Cancer 9: 282, 2009.

40. Antalis TM, Reeder JA, Gotley DC, Byeon MK, Walsh MD Henderson KW, Papas TS and Schweinfest CW: Down-regulation of the down-regulated in adenoma (DRA) gene correlates with colon tumor progression. Clin Cancer Res 4: 1857-1863, 1998.
41. Silberg DG, Wang W, Moseley RH and Traber PG: The down regulated in adenoma (dra) gene encodes an intestine-specific membrane sulfate transport protein. J Biol Chem 270: 11897-11902, 1995

42. Schweinfest CW, Spyropoulos DD, Henderson KW, Kim JH, Chapman JM, Barone S, Worrell RT, Wang Z and Soleimani M: Slc26a3 (dra)-deficient mice display chloride-losing diarrhea, enhanced colonic proliferation and distinct up-regulation of ion transporters in the colon. J Biol Chem 281: 37962-37971, 2006.

43. Chapman JM, Knoepp SM, Byeon MK, Henderson KW and Schweinfest CW: The colon anion transporter, down-regulated in adenoma, induces growth suppression that is abrogated by E1A. Cancer Res 62: 5083-5088, 2002

44. Hemminki A, Höglund P, Pukkala E, Salovaara R, Järvinen H, Norio R and Aaltonen LA: Intestinal cancer in patients with a germline mutation in the down-regulated in adenoma (DRA) gene. Oncogene 16: 681-684, 1998 .

45. Consortium The UniProt: http://www.uniprot. org/uniprot/Q01118. Accessed 18.07.15.

46. The Human Protein Atlas. http://www.proteinatlas. org/ENSG00000136546-SCN7A/gene. Accessed 18.07.15.

47. Juhlin CC, Goh G, Healy JM, Fonseca AL, Scholl UI, Stenman A, Kunstman JW, Brown TC, Overton JD, Mane SM, et al: Whole-exome sequencing characterizes the landscape of somatic mutations and copy number alterations in adrenocortical carcinoma. J Clin Endocrinol Metab 100: E493-E502, 2015.

48. Hubbard K, Catalano J, Puri RK and Gnatt A: Knockdown of TFIIS by RNA silencing inhibits cancer cell proliferation and induces apoptosis. BMC Cancer 8: 133, 2008.

49. Shema E, Kim J, Roeder RG and Oren M: RNF20 inhibits TFIIS-facilitated transcriptional elongation to suppress pro-oncogenic gene expression. Mol Cell 42: 477-488, 2011.

50. Zougman A, Hutchins GG, Cairns DA, Verghese E, Perry SL, Jayne DG, Selby PJ and Banks RE: Retinoic acid-induced protein 3: Identification and characterisation of a novel prognostic colon cancer biomarker. Eur J Cancer 49: 531-539, 2013.

51. Kume H, Muraoka S, Kuga T, Adachi J, Narumi R, Watanabe S, Kuwano M, Kodera Y, Matsushita K and Fukuoka J: Discovery of colorectal cancer biomarker candidates by membrane proteomic analysis and subsequent verification using selected reaction monitoring (SRM) and tissue microarray (TMA) analysis. Mol Cell Proteomics 13: 1471-1484, 2014. 